\title{
Foliar application of plant growth regulators to 'Crimson Seedless' grapevine influences leaf age
}

\author{
Amanda Cristina Esteves Amaro ${ }^{1 *}$, Essione Ribeiro Souza ${ }^{1}$, Laíse Sousa Santos ${ }^{2}$, Daniel Baron ${ }^{3}$, Elizabeth \\ Orika Ono ${ }^{4}$, João Domingos Rodrigues ${ }^{4}$ \\ ${ }^{1}$ Faculdade de Ciências Agronômicas (FCA), Universidade Estadual Paulista “Júlio de Mesquita Filho" (UNESP), \\ Botucatu Campus, Horticulture Department. CP-237, 18603-970, Botucatu-SP, Brazil \\ ${ }^{2}$ Universidade do Estado da Bahia, Department of Technology and Social Sciences, Campus de Juazeiro, Av. Edgar \\ Chastnet, s/n, CEP: 48900-000, Juazeiro-BA, Brazil \\ ${ }^{3}$ Centro de Ciências da Natureza (CCN), Universidade Federal de São Carlos (UFSCar), Lagoa do Sino Campus, Plant \\ Physiology and Biochemistry Laboratory. CP-094, 18290-000, Buri-SP, Brazil \\ 4Instituto de Biociências (IB), Universidade Estadual Paulista “Júlio de Mesquita Filho" (UNESP), Botucatu Campus, \\ Botany Department, CP-510, 18618-970, Botucatu-SP, Brazil
}

\section{*Corresponding author: amandaceamaro@gmail.com}

Abstract

\begin{abstract}
We hypothesized that phytohormones and essential mineral nutrients influence the duration of leaf photosynthetic activity, fruit production and quality. We used a randomized block design, with four treatments and six replicates. Two commercial products were studied: Stimulate (Stim), which is composed of a mixture of $0.009 \%$ cytokinin [N6-furfuryladenine or kinetin (Kt)], $0.005 \%$ auxin [4-indole-3-butyric acid (IBA)], and $0.005 \%$ gibberellin [gibberellic acid $\left(\mathrm{GA}_{3}\right)$ ], and Hold (CoMo), which is composed of $2 \%$ cobalt and 3\% molybdenum. These products were applied alone or in combination at different concentrations as follows: $T_{1}$ control, $\mathrm{T}_{2}-1.8 \mathrm{~L} \mathrm{ha}^{-1} \mathrm{Stim}, \mathrm{T}_{3}-1.8 \mathrm{~L} \mathrm{ha}^{-1} \mathrm{Stim}+1.0 \mathrm{~L} \mathrm{ha}^{-1} \mathrm{CoMo}$, and $\mathrm{T}_{4}-1.8 \mathrm{~L} \mathrm{~h}^{-1} \mathrm{Stim}+1.5 \mathrm{~L} \mathrm{ha}^{-1}$ CoMo. The treatments were applied via foliar spraying at three phases: the inflorescence primordial stage (19 days after pruning [DAP]), the point at which the berries were 6 to $8 \mathrm{~mm}$ in diameter (49 DAP), and the initiation of berry elongation (56 DAP). We revealed that in semiarid conditions, the grapevines were characterized by evergreen leaves (do not lose their leaves) that maintained their photosynthetic capacity throughout their lifecycles (133 days after sprouting). The application of Stim alone $\left(\mathrm{T}_{2}\right)$ yielded the maximal net $\mathrm{CO}_{2}$ assimilation rates and increased the carboxylation efficiencies, which indicated that this treatment might improve the photosynthetic output. These effects led to increases in the average mass, total length and width of the clusters per plant and decreased acidity level. Thus, we recommend the application of $T_{2}$ for grapevines.
\end{abstract}

Keywords: auxin; cobalt; cytokinin; gibberellin; molybdenum; Vitis vinifera L.

'Crimson Seedless' is a red, seedless, and late-season grape cultivar and one of the most consumed table grapes in the world (Conesa et al., 2016). Its berries are firm, crunchy, flavorful, and oblong in shape, but inadequate coloration and a small size might detract from their quality (Dokoozlian and Peacock, 2001). Because these small berries do not meet the size requirements of the export market, plant growth regulators are typically applied to promote growth (Tang et al., 2009).

Leaves play primary roles in the photosynthetic process, and essential mineral nutrients and energy are required for this process during plant development; however, this investment is later compensated when leaves become a source of nutrients after reaching photosynthetic competence (Rustioni et al., 2018). A reduction in the photosynthetic rate might be considered a sign of leaf senescence (Nogueira-
Júnior et al., 2018). The initiation of leaf senescence is an important process that remains to be elucidated, and its duration is also unclear. In addition, studies investigating approaches for slowing this process, e.g., the expression of genes related to phytohormone synthesis and/or hormone signaling (Upadhyay et al., 2018), might contribute to improvements in productivity and to the maintenance of photosynthetic activity for a longer duration (Lim et al., 2003; Quirino et al., 2000).

Plant hormones play important roles in controlling leaf senescence. For example, cytokinin and ethylene are the most well-defined hormones and participate in the slowing and induction of leaf senescence, respectively (Vylícilová, 2016; Dubois et al., 2018). During leaf development, hormones that slow aging processes, such as auxin, gibberellin, and cytokinin have less activities, whereas the 
activities of hormones that accelerate aging processes, such as ethylene, abscisic acid, and jasmonates, gradually increase (Chen and Dong, 2016).

In addition to plant hormones, cobalt also plays an important role in delaying leaf senescence (Vidya-Vardhini, 2017) by thwarting chlorophyll degradation through the inhibition of ethylene biosynthesis via prevention of the conversion of 1-aminocyclopropane-1-carboxylic acid (ACC) to ethylene. This reaction is catalyzed by ACC oxidase and represents the last step in the biosynthesis of ethylene (Lau and Yang, 1976; Yu and Yang, 1979).

Several physiological responses of plants to plant growth regulators and mineral nutrients are detailed in the literature, but the effects of these hormones on the duration of leaf photosynthetic activity are not well known. Therefore, we evaluated whether the foliar application of an auxin (Ax), cytokinin (CK), and gibberellin (GA) mixture alone or in combination with a Co and Mo mixture to 'Crimson Seedless' grapevines influences the duration of photosynthetic activity and the production and quality of the fruit.

\section{Results and discussion}

The variations in the photosynthetic photon flux density (PPFD), temperature, and relative humidity levels that were recorded during the gas exchange evaluation period from 7 to 133 days after sprouting (DAS) are shown in Table 1 . The PPFD ranged from 1417 to $1937 \mu \mathrm{mol} \mathrm{m} \mathrm{m}^{-1}$, which indicated that all of the plants experienced high levels of daytime sun exposure. The air temperatures ranged from $28.99{ }^{\circ} \mathrm{C}$ to $33.72{ }^{\circ} \mathrm{C}$, and the relative humidity ranged from $26.04 \%$ to $44.73 \%$. These findings revealed that the study area was exposed to high temperatures accompanied by low relative humidity levels throughout the study, which is characteristic of the region.

\section{Gas exchange evaluations}

Leaf development in perennial woody plants, such as grapevines, follows a well-defined sequence consisting of emergence, breakdown, leaf blade expansion, and subsequent senescence and abscission (Kriedemann et al., 1970). However, under the conditions of the Submedium Vale do São Francisco in the Brazilian semiarid region, the grapevines are grown under irrigation and are characterized by evergreen leaves that maintain their photosynthetic capacities throughout their lifecycles. These characteristics are in concordance with the findings of this experiment, which showed that the net $\mathrm{CO}_{2}$ assimilation rates were maintained, albeit sometimes at lower levels, at 133 DAS with all of the treatments (Fig 1). The plants did not naturally enter dormancy; instead, dormancy was chemically induced through the application of ethylene and a $50 \%$ reduction in the irrigation amount.

By 7 DAS, the leaves, which has small leaf areas, exhibited net $\mathrm{CO}_{2}$ assimilation rates, regardless of the treatment, which indicated that the young leaves were photosynthetically efficient. The application of plant growth regulators prompted the leaves to reach significantly higher maximal net $\mathrm{CO}_{2}$ assimilation rates, as demonstrated by Tukey's test $(p \leq 0.05)$. Furthermore, the net $\mathrm{CO}_{2}$ assimilation rates of the leaves peaked from 27 to 37 DAS, which was approximately four weeks after the peak time found for the seedling leaves. The leaves of the control plants $\left(\mathrm{T}_{1}\right)$ showed a maximal $\mathrm{CO}_{2}$ assimilation rate of 12.11 $\mu \mathrm{mol} \mathrm{m} \mathrm{s}^{-2}$ at 27 DAS, whereas the plants that were treated with the plant growth regulators $\left(T_{2}\right)$ showed maximal rates of $14.29 \mu \mathrm{mol} \mathrm{m} \mathrm{s}^{-1}$ at 37 DAS.

These results are in concordance with those reported by Jackson (2008) and Kriedemann et al. (1970), who found that within two to three weeks after the sprouting of vine leaves, nutrient transport essentially occurs toward the apex of the branches, and the leaves rely on carbohydrates and nitrogen compounds stored in other parts of the plant. Thus, at this time, the plants have not reached their maximal photosynthetic capacities. In addition, the grapevine biomass shows a significant response to different climatic conditions and management methods, and these responses directly reflect the leaf photosynthetic duration. The maximal photosynthetic rates are reached approximately 30 to 40 DAS, when the leaves are fully expanded, and thereafter remain stable for an extended period of time before decreasing.

Bertamini and Nedunchezhian $(2002,2003)$ also studied the influence of leaf age on vine leaves and classified leaves as follows: expanding leaves (5-10 DAS), newly expanded leaves (15-20 DAS), mature leaves (35-40 DAS), old mature leaves (65-70 DAS), and senescent yellow leaves (100-120 DAS). These researchers also found that the chlorophyll, carotenoid, and protein concentrations, Rubisco enzyme activities, and electron transport are increased during leaf development, reach their peaks in mature leaves, and then typically decrease. Dhami et al. (2018) reported that young leaves of Arabidopsis thaliana L. utilize additional photosynthetic carbon to increase their carotenoid content; however, older leaves of this plant exhibit a decreased ability to convert carbon into accessory pigments (e.g., carotenoids).

The stomatal conductance (Fig 2) obtained with all of the treatments was statistically similar, which indicated that the changes in the net $\mathrm{CO}_{2}$ assimilation rates were not the result of an increase in the size of the stomatal opening but rather due to greater carboxylation efficiencies. The leaves of the plants treated with the mixture of plant growth regulators alone $\left(T_{2}\right)$ or in combination with the nutrient mixture at 1.5 $L \mathrm{ha}^{-1}\left(\mathrm{~T}_{4}\right)$ reached their maximal (and peak) carboxylation efficiencies earlier (Fig 3; at 38 and 35 DAS, respectively) than the control plants (43 DAS), and this difference was statistically significant according to Tukey's test $(p \leq 0.05)$ and explains the higher net $\mathrm{CO}_{2}$ assimilation rates observed in the plants treated with plant growth regulators.

The treatments with the plant growth regulator mixture alone $\left(T_{2}\right)$ or in combination with nutrients at $1.5 \mathrm{~L} \mathrm{ha}^{-1}\left(\mathrm{~T}_{4}\right)$ led to increased net $\mathrm{CO}_{2}$ assimilation rates (Fig 1) starting at 21 DAS, which was 17 days after the initiation of the treatment. This increase can be verified by the steeper incline of the curves but was still lower than that of the control plants. Moreover, until approximately 63 DAS, the plants treated with the mixture of plant growth regulators $\left(T_{2}\right)$ alone showed higher net $\mathrm{CO}_{2}$ assimilation rates (Fig 1) and carboxylation efficiencies (Fig 3) than those administered the other treatments, and these differences were significance according to Tukey's test $(p \leq 0.05)$. The transpiration rates (Fig 4) and water-use efficiencies (Fig 5) of the plants, regardless of the treatment, were similar, and 
the maximal water-use efficiency was observed at 36 DAS. This finding indicated that the tested treatments had little influence on these variables.

The exogenous application of cytokinin reportedly increases the activity of the Rubisco enzyme and thereby optimized the carboxylation efficiency (Criado et al., 2009). This finding was also observed in this study, which indicates that the increase in the net $\mathrm{CO}_{2}$ assimilation rates was not due to an increase in the size of the stomatal opening.

The application of cytokinin also typically increases level of chlorophyll, which is an essential pigment for photosynthesis, in the leaves (Criado et al., 2009; Yang et al., 2003; Mangieri et al., 2017). This plant hormone decreases the degradation of chlorophyll and thereby contributes to the maintenance of photosynthesis. Another hormone that assists in maintaining the chlorophyll level is gibberellin, which also slows the breakdown of chlorophyll and proteins (Yan et al., 2017; Toscano et al., 2018).

Auxins influence carbohydrate partitioning by stimulating the mobilization of carbohydrates from the leaves and stem apex and promote the translocation of assimilates to drain organs by participating in vascular development (Chu et al., 2010; Scarpella, 2017). Similarly to cytokinins, these hormones induce the differentiation of tracheary xylem elements, and through this mechanism, auxins initiate vascular stem connections, induce the formation of new vascular components from parenchymal cells, and thereby influence the translocation of assimilates (Berleth et al., 2000; Werner and Schmülling 2009).

The positive effects of the tested treatment are evidenced by the increases in the net $\mathrm{CO}_{2}$ assimilation rates and carboxylation efficiencies observed from 14 to 21 days after the treatment. Furthermore, at 60 DAS, the plants began to show a reduced gas exchange, which was also described by Bertamini and Nedunchezhian $(2002,2003)$. Nevertheless, the plants treated with the mixture of plant growth regulators $\left(T_{2}\right)$ alone showed higher net $\mathrm{CO}_{2}$ assimilation rates and carboxylation efficiencies those administered the other treatments until approximately 63 DAS, which was 22 days after the third application of the treatment, and after 63 DAS, the net $\mathrm{CO}_{2}$ assimilation rates and carboxylation efficiencies began to decline. These results suggested that the application of plant growth regulators positively affected gas exchange for approximately 22 days, and because these effects subsequently decreased, the treatments need to be reapplied to maintain their positive effects, as demonstrated with the second and third applications of the treatments.

The reduced gas exchange rates that occurred during fruit harvest were likely due to the intense drain force exerted by the fruit and seeds that developed after flowering. The leaves largely determine the production, quality, and adaptation of plants to their environment; thus, the metabolic and physiological regulation of leaf senescence is of great agronomic interest. However, the plants treated with the mixture of plant growth regulators alone $\left(T_{2}\right)$ showed increased net $\mathrm{CO}_{2}$ assimilation rates and carboxylation efficiencies after the harvest period, which contributed to the accumulation of reserves that are used for plant recovery during the next production period.

Plant hormones play an important role in controlling leaf senescence, and the hormone cytokinin has a more pronounced effect in delaying leaf senescence because it inhibits the degradation of chlorophyll. Thus, exogenous applications of this plant hormone can delay the process of leaf senescence because, in addition to its relationship with the signaling pathways associated with senescence, it also participates in the regulation of auxin and sugars and the maintenance of photosynthesis (Shwartz, 2016). Furthermore, extracellular invertase activity is correlated with the cytokinin concentration. A decrease in the activity of this enzyme results in a delay in leaf senescence, which suggests that this hormone plays a role in this process because invertase activity increases during carbohydrate partitioning, which acts as a marker for leaf senescence (Sarwat et al., 2013).

Ethylene is responsible for the acceleration of leaf senescence. The application of Co can interfere with its synthesis by preventing the conversion of ACC to ethylene through the reaction catalyzed by ACC oxidase (Lau and Yang, 1976; Yu and Yang, 1979). However, this result was not observed in this experiment: the treatments with micronutrients did not prevent senescence and showed similar results to the control plants.

Furthermore, the plants treated with nutrients $\left(T_{3}\right.$ and $\left.T_{4}\right)$ showed a decreased gas exchange (Fig 1, 2, 3, 4 and 5) compared with those treated with the plant growth regulator mixture alone. This phenomenon was also observed by Reddy (1988), who found that plants treated with Co showed decreased rates of stomatal opening and consequently reduced transpiration. Furthermore, Mo is a cofactor of the enzyme nitrate reductase, which converts nitrite to nitric oxide using $\mathrm{NAD}(\mathrm{P}) \mathrm{H}$ as an electron donor and also converts nitrate to nitrite. Nitric oxide is involved in stomata closure and consequently in reducing transpiration in response to abscisic acid (ABA). $A B A$ induces the formation of nitric oxide in guard cells by nitrate reductase, but a previous study showed that this phenomenon is not restricted to these cells (Neill et al., 2008).

Molybdenum can also reduce the rates of stomatal opening because it is a cofactor of the enzyme aldehyde oxidase and increases the synthesis of $A B A$ by catalyzing the conversion of aldehyde to $A B A$, which is the final step in this pathway. Thus, the presence of this micronutrient can increase the $A B A$ levels and thereby reduce the rates of stomatal opening (Broadley et al., 2012).

This study showed that fruit harvest directly influenced the net $\mathrm{CO}_{2}$ assimilation rates because a marked reduction in the net $\mathrm{CO}_{2}$ assimilation rates was observed at the initiation of the harvesting period (from 119 to 133 days after pruning [DAP]). However, the plants treated with the mixture of plant growth regulators alone $\left(T_{2}\right)$ showed increases in their net $\mathrm{CO}_{2}$ assimilation rate and carboxylation efficiencies after the final harvest, and these rates were significantly higher than those found with the other treatments, as demonstrated by Tukey's test $(p \leq 0.05)$. This finding indicated the effectiveness of this treatment in increasing gas exchange.

\section{Fruit production}

The increase in the efficiency of gas exchange detected in the plants treated with the plant growth regulator mixture resulted in larger and more massive clusters.

The plants treated with the mixture of plant growth regulators alone $\left(T_{2}\right)$ exhibited the highest values for total cluster mass per plant, length and width of the clusters, and 
Table 1. Air temperature $\left({ }^{\circ} \mathrm{C}\right)$, relative humidity $(\%)$ and photosynthetic photon flux density (PPFD, $\left.\mu \mathrm{mol} \mathrm{m} \mathrm{m}^{-2} \mathrm{~s}^{-1}\right)$ obtained during the evaluation period of gas exchange in 'Crimson Seedless' grapevines from 7 to 133 days after sprouting (DAS).

\begin{tabular}{llll}
\hline $\begin{array}{l}\text { Days after sprouting } \\
(\mathrm{DAS})\end{array}$ & $\begin{array}{l}\text { Air temperature } \\
\left({ }^{\circ} \mathrm{C}\right)\end{array}$ & $\begin{array}{l}\text { Relative humidity } \\
(\%)\end{array}$ & $\begin{array}{l}\text { PPFD } \\
\left(\mu \mathrm{mol} \mathrm{m} \mathrm{m}^{-2}\right)\end{array}$ \\
\hline 7 & 33.35 & 36.09 & 1747.34 \\
4 & 28.99 & 43.33 & 1538.86 \\
21 & 29.30 & 40.37 & 1609.84 \\
28 & 31.67 & 42.26 & 1909.12 \\
35 & 27.19 & 44.73 & 1559.87 \\
42 & 29.03 & 40.32 & 1839.39 \\
49 & 31.85 & 31.70 & 1648.06 \\
56 & 30.27 & 33.34 & 1702.48 \\
63 & 32.26 & 26.04 & 1478.81 \\
70 & 30.65 & 38.99 & 1425.13 \\
77 & 31.91 & 33.24 & 1428.98 \\
84 & 33.00 & 30.64 & 1937.23 \\
91 & 33.64 & 32.64 & 1595.27 \\
98 & 30.95 & 36.57 & 1416.85 \\
105 & 33.72 & 29.40 & 1885.56 \\
112 & 33.55 & 36.15 & 1822.01 \\
119 & 31.48 & 44.09 & 1763.41 \\
126 & 33.33 & 36.29 & 1765.47 \\
133 & 31.30 & 38.40 & 1651.21 \\
\hline
\end{tabular}

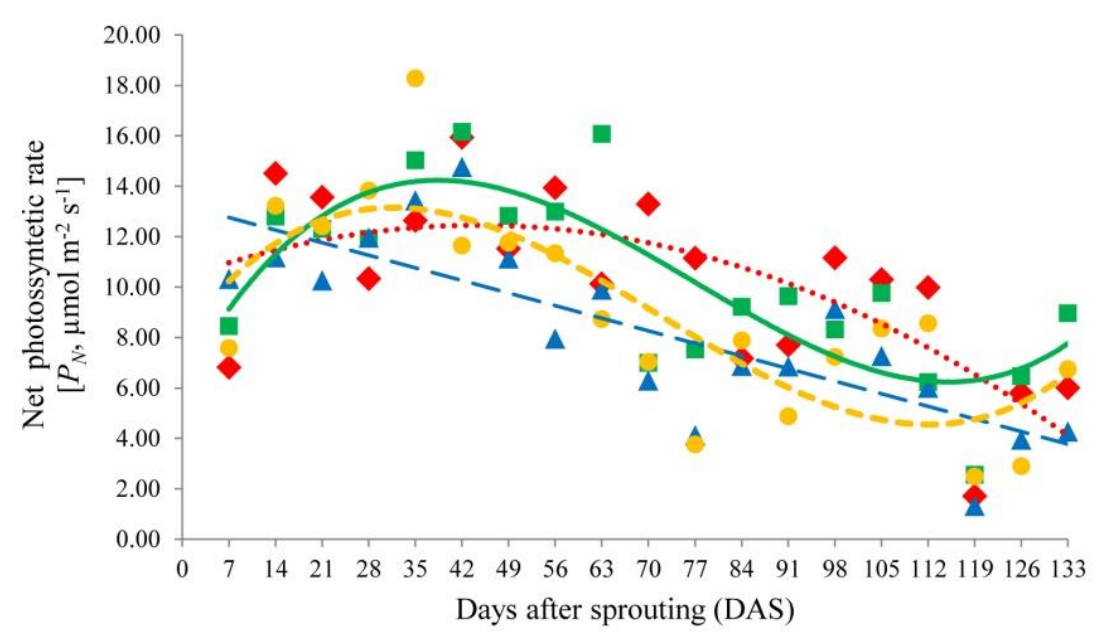

Fig 1. Net $\mathrm{CO}_{2}$ assimilation rate $\left(P_{N}, \mu \mathrm{mol} \mathrm{m} \mathrm{m}^{-2} \mathrm{~s}^{-1}\right)$ in the leaves of 'Crimson Seedless' grapevines treated with plant growth regulators alone or in combination with nutrients $(n=6)\left(T_{1}-\right.$ control treatment $\cdots, \cdots, T_{2}-1.8 \mathrm{~L} \mathrm{ha}^{-1} \mathrm{Stim} \boxminus-, \mathrm{T}_{3}-1.8 \mathrm{~L} \mathrm{ha}{ }^{-1} \mathrm{Stim}+1.0$ $\mathrm{L} \mathrm{ha}^{-1}$ CoMo $\boldsymbol{\Delta}--$, and $\mathrm{T}_{4}-1.8 \mathrm{~L} \mathrm{~h}^{-1} \mathrm{Stim}+1.5 \mathrm{~L} \mathrm{ha}{ }^{-1}$ CoMo $\left.\bullet . .-\right)$ ) during leaf development. Equations: $\mathrm{T}_{1}: \mathrm{y}=-0.001 \mathrm{x}^{2}+0.09 \mathrm{x}+$ 10.36; T2: $y=0.00004 x^{3}-0.01 x^{2}+0.47 x+6.14 ; T 3: y=-0.07 x+13.27 ; T 4 y=0.00003 x^{3}-0.01 x^{2}+0.38 x+7.32$

Table 2. Total mass of the clusters per plant (TCM, $\mathrm{kg}$ ), average cluster mass (CM, g), length of the clusters (LC, cm), width of the clusters (WC, cm), fresh weight of the rachis (FWR, g), dry mass of the rachis (DMR, g), rachis apex diameter (RAD, mm), rachis intermediate diameter (RID, $\mathrm{mm}$ ), and rachis base diameter (RBD, $\mathrm{mm}$ ) in 'Crimson Seedless' grapevines treated with plant growth regulators alone or in combination with nutrients $\left(\mathrm{T}_{1}\right.$ - control treatment, $\mathrm{T}_{2}-1.8 \mathrm{~L} \mathrm{ha}^{-1} \mathrm{Stim}, \mathrm{T}_{3}-1.8 \mathrm{~L} \mathrm{ha}{ }^{-1} \mathrm{Stim}+1.0 \mathrm{~L} \mathrm{ha}{ }^{-1} \mathrm{CoMo}$, and $\mathrm{T}_{4}-1.8 \mathrm{~L} \mathrm{~h}^{-1}$ Stim $+1.5 \mathrm{~L} \mathrm{ha}^{-1}$ CoMo).

\begin{tabular}{llllllllll}
\hline Treatments & TCM $(\mathrm{kg})$ & $\begin{array}{l}\mathrm{CM} \\
(\mathrm{g})\end{array}$ & $\begin{array}{l}\mathrm{LC} \\
(\mathrm{cm})\end{array}$ & $\begin{array}{l}\text { WC } \\
(\mathrm{cm})\end{array}$ & $\begin{array}{l}\text { FWR } \\
(\mathrm{g})\end{array}$ & $\begin{array}{l}\text { DMR } \\
(\mathrm{g})\end{array}$ & $\begin{array}{l}\text { RAD } \\
(\mathrm{mm})\end{array}$ & $\begin{array}{l}\text { RID } \\
(\mathrm{mm})\end{array}$ & $\begin{array}{l}\text { RBD } \\
(\mathrm{mm})\end{array}$ \\
\hline $\mathrm{T}_{1}$ & $25.43 \mathrm{~b}$ & $364.48 \mathrm{~b}$ & $17.64 \mathrm{~b}$ & $11.37 \mathrm{~b}$ & 8.96 & 2.91 & 4.96 & 3.06 & 2.42 \\
$\mathrm{~T}_{2}$ & $36.82 \mathrm{a}$ & $556.75 \mathrm{a}$ & $20.94 \mathrm{a}$ & $14.44 \mathrm{a}$ & 13.00 & 4.50 & 4.75 & 3.48 & 2.58 \\
$\mathrm{~T}_{3}$ & $29.4 \mathrm{~b}$ & $526.46 \mathrm{a}$ & $19.91 \mathrm{~b}$ & $13.57 \mathrm{ab}$ & 11.67 & 3.86 & 5.14 & 3.63 & 2.79 \\
$\mathrm{~T}_{4}$ & $28.41 \mathrm{~b}$ & $505.62 \mathrm{ab}$ & $20.23 \mathrm{~b}$ & $13.60 \mathrm{ab}$ & 10.75 & 3.61 & 4.96 & 3.60 & 2.78 \\
\hline $\mathrm{Pr}>\mathrm{F}$ & $12.91^{* *}$ & $5.26^{*}$ & $7.05^{* *}$ & $3.61^{*}$ & $2.44 \mathrm{~ns}$ & $2.22 \mathrm{~ns}$ & $0.21 \mathrm{~ns}$ & $1.67 \mathrm{~ns}$ & $0.98 \mathrm{~ns}$ \\
$\mathrm{C} . \mathrm{V} .(\%)$ & 8.97 & 15.21 & 5.46 & 10.42 & 23.98 & 28.96 & 13.99 & 11.78 & 13.61 \\
\hline
\end{tabular}

The means followed by the same letter do not differ significantly, as demonstrated by Tukey's test $(n=6)$. The double $(* *)$ and single $(*)$ asterisks indicate significant differences at the $1 \%(p<0.01)$ and $5 \%(p \geq 0.05)$ probability levels, respectively, and ns indicates a non-significant difference. 


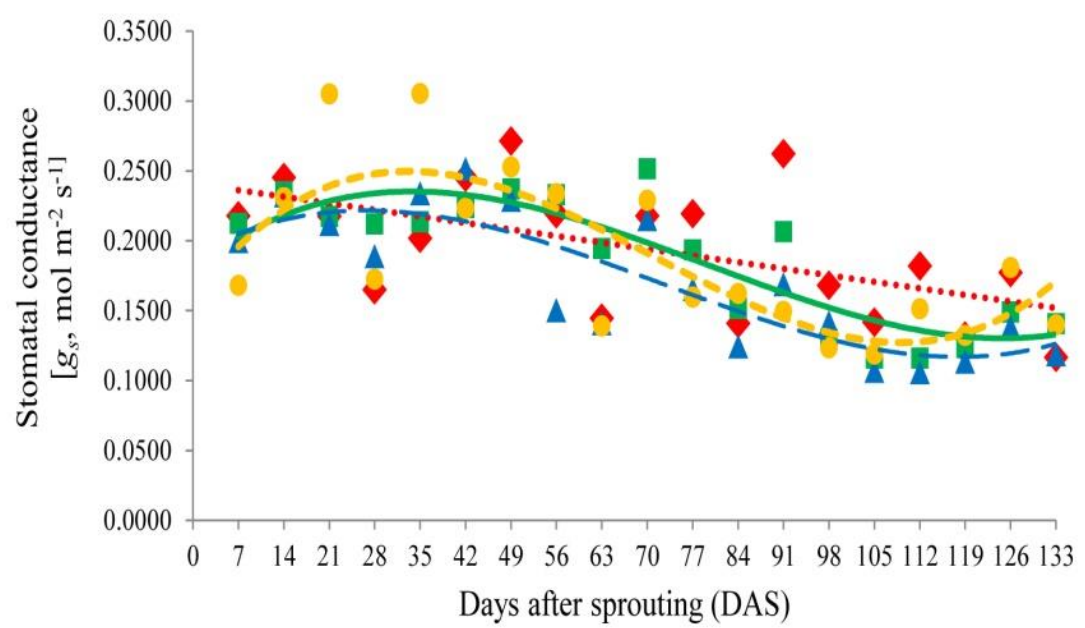

Fig 2. Stomatal conductance $\left(g_{s}, \mathrm{~mol} \mathrm{~m}^{-2} \mathrm{~s}^{-1}\right)$ in the leaves of 'Crimson Seedless' grapevines treated with plant growth regulators alone or in combination with nutrients $(n=6)\left(\mathrm{T}_{1}-\right.$ control treatment $\cdots, \mathrm{T}_{2}-1.8 \mathrm{~L} \mathrm{ha}^{-1} \mathrm{Stim}=-\mathrm{T}_{3}-1.8 \mathrm{~L} \mathrm{ha} \mathrm{C}^{-1} \mathrm{Stim}+1.0 \mathrm{~L} \mathrm{ha}{ }^{-1}$ CoMo $\Delta--$, and $\mathrm{T}_{4}-1.8 \mathrm{~L} \mathrm{~h}^{-1} \mathrm{Stim}+1.5 \mathrm{~L} \mathrm{ha}{ }^{-1}$ CoMo $\left.\bullet-..\right)$ ) during leaf development. Equations: $\mathrm{T} 1 \mathrm{y}=-0.0007 \mathrm{x}+0.24 ; \mathrm{T} 2 \mathrm{y}=$ $0.0000003 x^{3}-0.00007 x^{2}+0.003 x+0.18 ; T 3 y=0.0000003 x^{3}-0.00006 x^{2}+0.003 x+0.19 ;$ T4 $y=0.0000005 x^{3}-0.0001 x^{2}+0.006 x+$ 0.16 .

Table 3. Berry mass $(B M, g)$, berry length $(B L, m m)$, berry diameter $(B D, m m)$, berry volume (BV, $\mathrm{mL})$, soluble solid content (SS, ㅇ Brix), titratable acidity level (TA, g of tartaric/100 g pulp) and color of the berries (CB) in 'Crimson Seedless' grapevines treated with plant growth regulators alone or in combination with nutrients $\left(T_{1}-\right.$ control treatment, $\mathrm{T}_{2}-1.8 \mathrm{~L} \mathrm{ha}{ }^{-1} \mathrm{Stim}, \mathrm{T}_{3}-1.8 \mathrm{~L} \mathrm{ha}{ }^{-1} \mathrm{Stim}+1.0$ $\mathrm{L} \mathrm{ha}^{-1} \mathrm{CoMo}$, and $\left.\mathrm{T}_{4}-1.8 \mathrm{~L} \mathrm{~h}^{-1} \mathrm{Stim}+1.5 \mathrm{~L} \mathrm{ha}^{-1} \mathrm{CoMo}\right)$ during leaf development.

\begin{tabular}{llllllll}
\hline Treatments & $\begin{array}{l}\mathrm{BM} \\
(\mathrm{g})\end{array}$ & $\begin{array}{l}\mathrm{BL} \\
(\mathrm{mm})\end{array}$ & $\begin{array}{l}\mathrm{BD} \\
(\mathrm{mm})\end{array}$ & $\begin{array}{l}\mathrm{BV} \\
(\mathrm{mL})\end{array}$ & $\begin{array}{l}\text { SS } \\
\left({ }^{\circ} \text { Brix }\right)\end{array}$ & TA & $\mathrm{CB}$ \\
\hline $\mathrm{T}_{1}$ & 5.05 & 27.35 & $18.65 \mathrm{a}$ & $5.20 \mathrm{a}$ & 16.69 & $0.67 \mathrm{a}$ & 3.75 \\
$\mathrm{~T}_{2}$ & 4.71 & 25.22 & $17.72 \mathrm{~b}$ & $4.35 \mathrm{~b}$ & 17.65 & $0.56 \mathrm{~b}$ & 3.87 \\
$\mathrm{~T}_{3}$ & 4.67 & 26.22 & $17.60 \mathrm{~b}$ & $4.32 \mathrm{~b}$ & 16.63 & $0.57 \mathrm{ab}$ & 4.00 \\
$\mathrm{~T}_{4}$ & 4.94 & 26.40 & $17.75 \mathrm{~b}$ & $4.60 \mathrm{ab}$ & 16.26 & $0.60 \mathrm{ab}$ & 3.94 \\
\hline $\mathrm{Pr}>\mathrm{F}$ & $0.65 \mathrm{~ns}$ & $1.36 \mathrm{~ns}$ & $6.35^{* *}$ & $4.28^{*}$ & $0.80 \mathrm{~ns}$ & $4.61^{*}$ & $0.56 \mathrm{~ns}$ \\
$\mathrm{C} . \mathrm{V} .(\%)$ & 9.19 & 4.41 & 2.14 & 8.52 & 13.04 & 7.49 & 7.36 \\
\hline
\end{tabular}

The means followed by the same letter do not differ significantly, as demonstrated by Tukey's test $(n=6)$. The double $\left(^{* *}\right)$ and single $(*)$ asterisks indicate significant differences at the $1 \%(p<0.01)$ and $5 \%(p<0.05)$ probability levels, respectively, and ns denotes a non-significant difference $(p \geq 0.05)$.

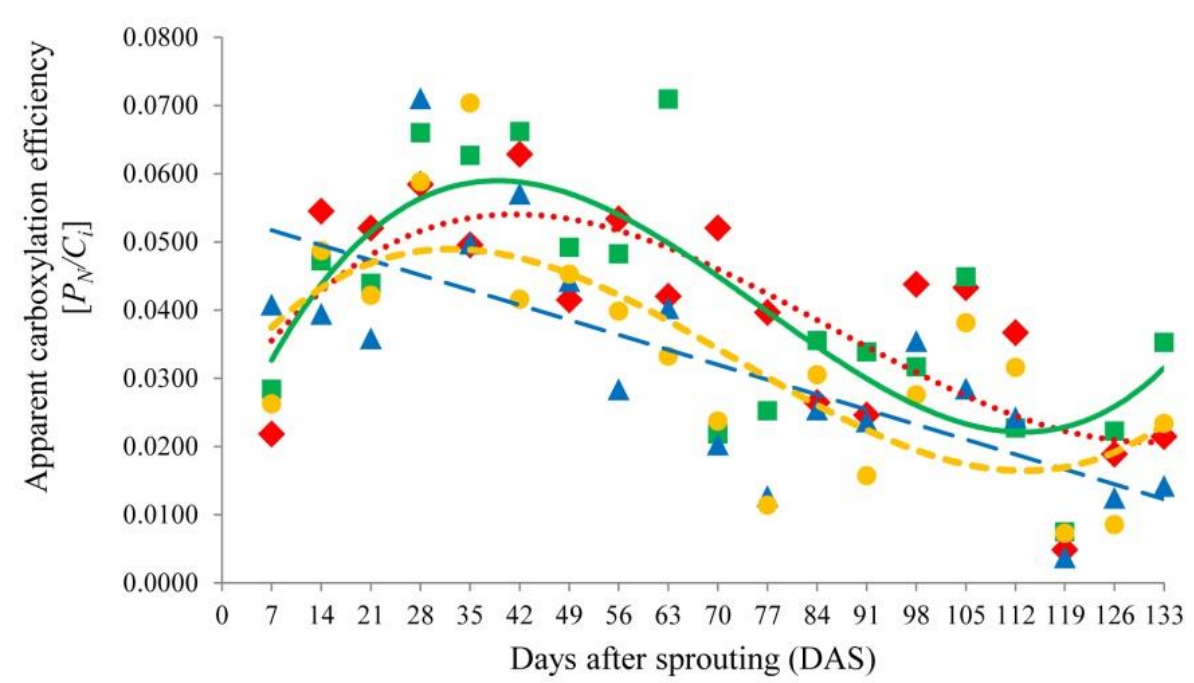

Fig 3. Apparent carboxylation efficiency $\left(P_{N} / C_{i}\right)$ in the leaves of 'Crimson Seedless' grapevines treated with plant growth regulators alone or in combination with nutrients $(n=6)\left(\mathrm{T}_{1}-\right.$ control treatment $\cdots, \mathrm{T}_{2}-1.8 \mathrm{~L} \mathrm{ha}^{-1} \mathrm{Stim} \backsim-, \mathrm{T}_{3}-1.8 \mathrm{~L} \mathrm{ha}{ }^{-1} \mathrm{Stim}+1.0 \mathrm{~L} \mathrm{ha}{ }^{-1}$ CoMo $\mathbf{\Delta}--$, and $\mathrm{T}_{4}-1.8 \mathrm{~L} \mathrm{~h}^{-1}$ Stim $+1.5 \mathrm{~L} \mathrm{ha}{ }^{-1}$ CoMo $\left.\bullet-.-\right)$ ) during leaf development. Equations: T1 $y=0.00000009 x^{3}-0.00002 x^{2}+$ $0.001 x+0.03 ; \mathrm{T} 2 \mathrm{y}=0.0000002 \mathrm{x}^{3}-0.00004 \mathrm{x}^{2}+0.002 \mathrm{x}+0.02 ; \mathrm{T} 3 \mathrm{y}=-0.0003 \mathrm{x}+0.05 ; \mathrm{T} 4 \mathrm{y}=0.0000001 \mathrm{x}^{3}-0.00003 \mathrm{x}^{2}+0.002 \mathrm{x}+0.02$ 


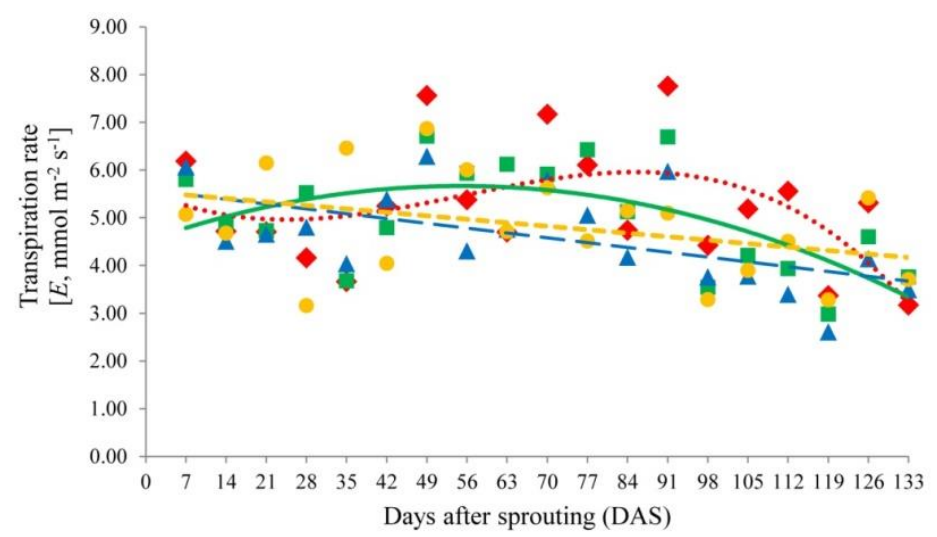

Fig 4. Transpiration rate $\left(E, \mathrm{mmol} \mathrm{m}^{-2} \mathrm{~s}^{-1}\right)$ in the leaves of 'Crimson Seedless' grapevines treated with plant growth regulators, alone or in combination with nutrients $(n=6)\left(\mathrm{T}_{1}-\right.$ control treatment $\cdots, \mathrm{T}_{2}-1.8 \mathrm{~L} \mathrm{ha}^{-1}$ Stim $\backsim-, \mathrm{T}_{3}-1.8 \mathrm{~L} \mathrm{ha}^{-1} \mathrm{Stim}+1.0 \mathrm{~L} \mathrm{ha}{ }^{-1} \mathrm{CoMo} \boldsymbol{\Delta}-$ - , and $\mathrm{T}_{4}-1.8 \mathrm{~L} \mathrm{~h}^{-1} \mathrm{Stim}+1.5 \mathrm{~L} \mathrm{ha}{ }^{-1}$ CoMo $\left.\bullet-\cdot\right)$ ) during leaf development. Equations: $\mathrm{T} 1 \mathrm{y}=-0.000009 \mathrm{x}^{3}+0.001 \mathrm{x}^{2}-0.05 \mathrm{x}+5.57 ; \mathrm{T} 2$ $y=-0.0004 x^{2}+0.04 x+4.51 ; T 3 y=-0.01 x+5.59 ; T 4 y=-0.01 x+5.72$

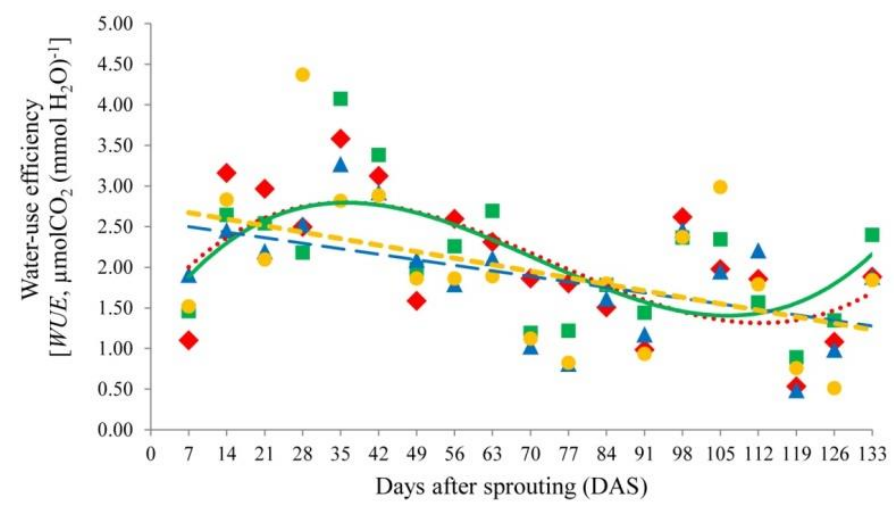

Fig 5. Water-use efficiency $\left.\left(W U E, \mu \mathrm{mol} \mathrm{CO}_{2}\left(\mathrm{mmol} \mathrm{H}_{2} \mathrm{O}\right)^{-1}\right)\right)$ in the leaves of 'Crimson Seedless' grapevines treated with plant growth regulators, alone or in combination with nutrients $(n=6)\left(\mathrm{T}_{1}-\right.$ control treatment $\bullet \cdots, \mathrm{T}_{2}-1.8 \mathrm{~L} \mathrm{ha}^{-1} \mathrm{Stim} \backsim-, \mathrm{T}_{3}-1.8 \mathrm{~L}$ ha ${ }^{-1} \mathrm{Stim}+$ $1.0 \mathrm{~L} \mathrm{ha}{ }^{-1}$ CoMo $\Delta--$, and $\mathrm{T}_{4}-1.8 \mathrm{~L} \mathrm{~h}^{-1} \mathrm{Stim}+1.5 \mathrm{~L} \mathrm{ha}^{-1}$ CoMo $\left.\bullet-..\right)$ ) during leaf development. Equations: $\mathrm{T} 1 \mathrm{y}=0.000006 \mathrm{x}^{3}-$ $0.001 x^{2}+0.08 x+1.51 ; T 2 y=0,000008 x^{3}-0.002 x^{2}+0.09 x+1,32 ;$ T3 $y=-0,010 x+2,57 ;$ T4 $y=-0.010 x+2.61$

average cluster mass; however, the average cluster mass of these plants did not differ significantly from that of the plants treated with nutrients $\left(\mathrm{T}_{3}\right.$ and $\left.\mathrm{T}_{4}\right)$ (Table 2). Additionally, no significant differences in the colors, lengths, and masses of the berries were observed between the treatments, but the plants treated with growth regulators $\left(T_{2}, T_{3}\right.$ and $\left.T_{4}\right)$ exhibited the smallest berry diameters and volumes (Table 3). Because the 'Crimson Seedless' grape is characterized by oblong berries, this grape typically has smaller diameters, which indicates that the berries are of higher quality. As shown in Table 3, the plants treated with the mixture of plant growth regulators alone $\left(T_{2}\right)$ or in combination with nutrients $\left(T_{3}\right.$ and $\left.T_{4}\right)$ showed lower acidity levels, which indicated that these plants produced higherquality berries. However, the plants treated with the mixture of plant growth regulators alone $\left(T_{2}\right)$ or in combination with the nutrients $\left(T_{3}\right.$ and $\left.T_{4}\right)$ had wider clusters, which indicated superior shoulder formation and greater mass. Cytokinins play important roles in the control of many structural aspects of the grapevines, including cluster growth and the setting and development of berries (Kanellis and RoubelakisAngelakis, 1993).
The application of forchlorfenuron (CPPU) or thidiazuron in the absence of purine cytokinins increases the cluster mass and berry size of the seedless variety as well as its setting and firmness (Han and Lee, 2004; Peppi and Fidelibus, 2008; Reynolds et al., 1992; Zabadal and Bukovac, 2006). The application of gibberellic acid $\left(\mathrm{GA}_{3}\right)$ to clusters of 'Thompson Seedless' grapevines increases the mass and diameter of the berries, the mass and length of the clusters and the concentration of soluble solids (SS, in ${ }^{\circ} \mathrm{Brix}$ ) and reduces the acidity, and these effects lead to improvements in the quality of the grapes. However, the combined application of cytokinin (CPPU) and gibberellin $\left(\mathrm{GA}_{3}\right)$ exerts synergistic effects, namely, increases in the size and weight of seedless grape berries and in the diameter of the rachis (Han and Lee 2004; Raban et al., 2013; Retamales et al., 1995; Reynolds et al., 1992; Zoffoli et al., 2009). Notably, no differences in the characteristics of the rachises were observed in this experiment. 
Materials and methods

\section{Experiment location and plant materials}

The experiment was conducted in a commercial vineyard located at $09^{\circ} 19^{\prime} 697^{\prime \prime} S$ and $40^{\circ} 11^{\prime} 416^{\prime \prime} \mathrm{W}$ in Juazeiro (BA), Brazil. According to the Köppen classification, the climate in this area is Bswh, which corresponds to a hot semiarid region.

The 'Crimson Seedless' (Vitis vinifera L.) seedless grape cultivar grafted onto rootstock 'IAC 313' (aged 4 years) was used. The plants were irrigated, separated by a distance of $3.0 \mathrm{~m}$ within rows and $3.5 \mathrm{~m}$ between rows and supported by a Y-type steering system.

\section{Treatments}

The experiments were conducted using a randomized block design consisting of four treatments and six blocks of four plants each and two useful plants.

The treatments were designed using two commercial products. The commercial product Stimulate, which is manufactured by Stoller of Brazil, is composed of a mixture of $0.009 \%$ cytokinin [N6-furfuryladenine or kinetin $(\mathrm{Kt})$ ], $0.005 \%$ auxin [4-indole-3-butyric acid (IBA)], and $0.005 \%$ gibberellin [gibberellic acid $\left(\mathrm{GA}_{3}\right)$ ] and was used as a source of plant growth regulators. The commercial product Hold, which is also manufactured by Stoller of Brazil, is composed of $2 \%$ cobalt and $3 \%$ molybdenum and was used as a source of cobalt and molybdenum. For clarity, the plant growth regulator and nutrient mixtures are abbreviated as "Stim" and "CoMo", respectively.

The $\mathrm{pH}$ of the solutions was acidified to 4.5 through the addition of phosphoric acid. The commercial product Natur'l Oil $(0.25 \%)$, which is also produced by Stoller of Brazil and is composed of $93 \%$ vegetable oil, was used as an adhesive spreader. Therefore, water acidified to $\mathrm{pH} 4.5$ supplemented with $0.25 \%$ vegetable oil solution comprised the control treatment.

The treatments were designed using the commercial products alone or in combination at different concentrations as follows: $T_{1}$ - control treatment, $\mathrm{T}_{2}-1.8 \mathrm{~L} \mathrm{~h}{ }^{-1} \mathrm{Stim}, \mathrm{T}_{3}-1.8$ $\mathrm{L} \mathrm{ha}^{-1}$ Stim $+1.0 \mathrm{~L} \mathrm{ha}^{-1}$ CoMo, and $\mathrm{T}_{4}-1.8 \mathrm{~L} \mathrm{~h}^{-1}$ Stim $+1.5 \mathrm{~L}$ $\mathrm{ha}^{-1}$ CoMo.

The treatments were applied via foliar spraying using a backpack sprayer at three phases, namely the inflorescence primordial stage (19 days after pruning [DAP]), the point at which the berries were 6 to $8 \mathrm{~mm}$ in diameter (49 DAP), and the initiation of berry elongation (56 DAP).

\section{Gas exchange evaluations}

To assess the duration of photosynthetic activity, the gas exchange levels were monitored starting soon after sprouting. The first evaluation was performed 7 days after sprouting, and for the assessment, leaves were placed in a chamber with equipment for measuring photosynthesis. The evaluations were performed every seven days from $09 \mathrm{~h} 00$ to $11 \mathrm{~h} 00$, and the measurements were obtained using the same leaf in an attempt to assess the evolution of gas exchange and the duration of leaf photosynthetic capacity up to 133 DAS, which was when, according to the farm management, leaf abscission was chemically induced through ethephon application.

The gas exchange levels were measured with an infrared $\mathrm{CO}_{2}$ and water vapor analyzer (LI-6400, Li-Cor Inc., Lincoln, NE, USA). The net $\mathrm{CO}_{2}$ assimilation rates $\left(\mathrm{P}_{\mathrm{N}}, \mu \mathrm{mol} \mathrm{CO}_{2} \mathrm{~m}^{-2} \mathrm{~s}^{-1}\right)$, transpiration rates $\left(E, \quad m o l \quad \mathrm{H}_{2} \mathrm{O} \quad \mathrm{m}^{-2} \mathrm{~s}^{-1}\right)$, stomatal

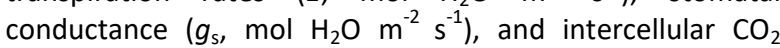
concentrations $\left(C_{i}, \mu \mathrm{mol} \mathrm{CO} \mathrm{Col}_{2} \mathrm{air}^{-1}\right)$ were evaluated.

The water-use efficiency [WUE, $\left.\mu \mathrm{mol} \mathrm{CO}_{2}\left(\mathrm{~mol} \mathrm{H}_{2} \mathrm{O}\right)^{-1}\right]$ was determined based on the relationship between the net assimilation rate and the transpiration rate $\left(P_{N} / E\right)$, and the apparent carboxylation efficiency $\left(\mathrm{P}_{\mathrm{N}} / C_{\mathrm{i}}\right)$ was determined based on the relationship between the net $\mathrm{CO}_{2}$ assimilation rate and the intercellular $\mathrm{CO}_{2}$ concentration. The air temperature and relative humidity are expressed in units of degrees Celsius $\left({ }^{\circ} \mathrm{C}\right.$ ) and as a percentage (\%), respectively.

The PPFD was standardized through the use of a lightemitting diode that was coupled to a photosynthesis chamber and emitted $1,500 \mu \mathrm{mol} \mathrm{m} \mathrm{s}^{-2}$. The reference $\mathrm{CO}_{2}$ concentration used during the evaluation was the ambient value, which ranged from 385 to $395 \mathrm{\mu mol} \mathrm{mol}^{-1}$ air.

\section{Fruit production}

The fruit harvest period was split into four stages according to the berry colors and the SS content, which reached at least $16^{\circ}$ Brix at 110 DAP and titratable acidity (TA) levels of 0.6 at 131 DAP. All the fruits were weighed using an analytical balance.

For the biometric and biochemical analyses, two representative clusters of similar lengths were randomly collected per plot per replicate for each treatment, resulting in a total sample of 100 berries.

The total mass of the clusters per plant, average cluster weight ( $\mathrm{g})$, and fresh and dry weights of the rachises ( $\mathrm{g}$ ) were measured using an analytical balance. To determine the dry weights, the rachises were placed under forced air circulation at $65^{\circ} \mathrm{C}$ until a constant weight was reached.

The average lengths and widths of the clusters $(\mathrm{cm})$ were determined using a graduated scale. The diameters of the apices and intermediate and basal rachises were measured using a digital caliper just below the first secondary branching in the middle and at the base of the rachis. For the color evaluation, the colors of the bunches were scored from 1 to 4 , in which a higher score corresponds to a deeper color.

The fresh weight $(\mathrm{g})$, diameter $(\mathrm{mm})$, length $(\mathrm{mm})$, and average volume of the sample of 100 berries were measured in a beaker by determining the volume of displaced water after the introduction of the berries.

A manual digital refractometer was used to determine the SS content ( ${ }^{\circ}$ Brix), and the TA level ( $\mathrm{g}$ of tartaric acid/100 $\mathrm{g}$ of pulp) was measured using the titration method with $0.1 \mathrm{~N}$ $\mathrm{NaOH}$.

\section{Statistical analyses}

The data were subjected to an analysis of variance ( $F$-test), and the means were compared by Tukey's test based on a $5 \%$ probability level $(p \leq 0.05)$ and a regression analysis. The maximal values of the functions were determined whenever possible. To determine the homogeneity of the treatment 
variances, Levene's test was performed. SAS 9.2 statistical software was used for the statistical analyses.

\section{Conclusion}

Under the semiarid conditions in which this study was conducted, the grapevines are characterized by evergreen leaves that maintain their photosynthetic capacities throughout their lifecycles. The young leaves began to show net $\mathrm{CO}_{2}$ assimilation rates one week after sprouting, even with reduced leaf areas and regardless of the treatment, which indicates the photosynthetic efficiency of this cultivar. This increase in the photosynthetic rate resulted in increases in the mass and total lengths of the clusters per plant and in the widths and average cluster masses and a decreased acidity level and thereby improved the fruit quality. These findings confirmed our hypothesis and suggested that the application of plant growth regulators leads to maximal net $\mathrm{CO}_{2}$ assimilation rates and increased carboxylation efficiencies, which indicates that this treatment might improve the photosynthetic output.

\section{Acknowledgments}

The authors wish to thank the National Council for the Improvement of Higher Education (CAPES) for the scholarship grant and Dr. Martha Maria Mischan (Universidade Estadual Paulista, Instituto de Biociências, Biostatistics Department) for the substantial help provided with the statistical analyses.

\section{References}

Berleth T, Mattsson J, Hardtke CS (2000) Vascular continuity and auxin signals. Trends Plant Sci. 5:387-393.

Bertamini M, Nedunchezhian N (2002) Leaf age effects on chlorophyll, rubisco, photosynthetic electron transport activities and thylakoid membrane protein in field grown grapevine leaves. J Plant Physiol. 159:799-803.

Bertamini M, Nedunchezhian N (2003) Photoinhibition of photosynthesis in mature and young leaves of grapevine (Vitis vinifera L.). Plant Sci. 164:635-644.

Broadley M, Brown P, Cakmak I, Rengel Z, Zhao F (2012). Chapter 7 - Function of Nutrients: Micronutrients. In: Marschner P (ed) Marschner's Mineral Nutrition of Higher Plants, 3rd edn. Academic Press, San Diego. 191-248.

Chen Y, Dong H (2016) Mechanisms and regulation of senescence and maturity performance in cotton. Field Crop Res. 189:1-9.

Chu EP, Tavares AR, Kanashiro S, Giampaoli P, Yokota ES (2010) Effects of auxins on soluble carbohydrates, starch and soluble protein content in Aechmea blanchetiana (Bromeliaceae) cultured in vitro. Sci Hortic-Amsterdam. 125(3):451-455.

Conesa MR, Falagán N, de la Rosa JM, Aguayo E, Domingos $R$, Pastor AP (2016) Post-veraison deficit irrigation regimes enhance berry coloration and health-promoting bioactive compounds in 'Crimson Seedless' table grapes. Agr Water Manage. 163:9-18.

Criado MV, Caputo C, Roberts IN, Castro MA, Barneix AJ (2009) Cytokinin-induced changes of nitrogen remobilization and chloroplast ultrastructure in wheat (Triticum aestivum). J Plant Physiol. 166:1775-1785.
Dhami N, Tissue DT, Cazzonelli Cl (2018) Leaf-age dependent response of carotenoid accumulation to elevated $\mathrm{CO}_{2}$ in Arabidopsis. Arch Biochem Biophys. 647:67-75.

Dokoozlian N, Peacock W (2001) Gibberellic acid applied at bloom reduces fruit set and improves size of 'Crimson Seedless' table grapes. HortScience. 36:706-709.

Dubois M, Van Den Broeck L, Inzé D (2018) The Pivotal Role of Ethylene in Plant Growth. Trends Plant Sci. 23(4):311323.

Han DH, Lee CH (2004) The Effects of $\mathrm{GA}_{3}$, CPPU and ABA applications on the quality of Kyoho (Vitis vinifera $\mathrm{L}$. $x \mathrm{~V}$. labrusca L.) grape. Acta Hortic. 653:193-200.

Jackson RS (2008) 3 - Grapevine Structure and Function. In: Jackson RS (ed) Wine Science, 3rd edn. Academic Press, San Diego. 50-107.

Kanellis AK, Roubelakis-Angelakis KA (1993) Grape. In: Seymour GB, Taylor JE, Tucker GA (eds.) Biochemistry of Fruit Ripening. Springer, Netherlands. 189-234.

Kriedemann P, Kliewer W, Harris J (1970) Leaf age and photosynthesis in Vitis vinifera L.. Vitis. 9:97-104.

Lau O-L, Yang SF (1976) Inhibition of Ethylene Production by Cobaltous Ion. Plant Physiol. 58:114-117.

Lim PO, Woo HR, Nam HG (2003) Molecular genetics of leaf senescence in Arabidopsis. Trends Plant Sci. 8:272-278.

Mangieri, MA, Hall AJ, Striker GG, Chimenti CA (2017) Cytokinins: a key player in determining differences in patterns of canopy senescence in stay-green and fast drydown sunflower (Helianthus annuus L.) hybrids. Eur J Agron. 86:60-70.

Neill S, Barros R, Bright J, Desikan R, Hancock J, Harrison J, Morris P, Ribeiro D, Wilson (2008) Nitric oxide, stomatal closure, and abiotic stress. J Exp Bot. 59:165-176.

Nogueira Júnior AF, Amorim L, Savary S, Willocquet L (2018) Modelling the dynamics of grapevine growth over years. Ecol Model. 369:77-87.

Peppi MC, Fidelibus MW (2008) Effects of forchlorfenuron and abscisic acid on the quality of 'Flame Seedless' grapes. HortScience. 43:173-176.

Quirino BF, Noh YS, Himelblau E, Amasino RM (2000) Molecular aspects of leaf senescence. Trends Plant Sci. 5:278-282.

Raban E, Kaplunov T, Zutahy Y, Daus A, Alchanatis V, Viacheslav O, Lurie S, Lichter A (2013) Rachis browning in four table grape cultivars as affected by growth regulators or packaging. Postharvest Biol Tec. 84:88-95.

Reddy TV (1988) Mode of action of cobalt extending the vase life of cut roses. Sci Hortic-Amsterdam. 36:303-313.

Retamales J, Bangerth F, Cooper T, Callejas R (1995) Effects of CPPU and $\mathrm{GA}_{3}$ on fruit quality of Sultanina table grape. Acta Hortic. 394:149-158.

Reynolds AG, Wardle DA, Zurowski C, Looney NE (1992) Phenylureas CPPU and thidiazuron affect yield components, fruit composition, and storage potential of four seedless grape selections. J Am Soc Hortic Sci. 117: 85-89.

Rustioni L, Grossi D, Brancadoro L, Failla O (2018) Iron, magnesium, nitrogen and potassium deficiency symptom discrimination by reflectance spectroscopy in grapevine leaves. Sci Hortic-Amsterdam. 241:152-159.

Sarwat M, Naqvi AR, Ahmad P, Ashraf M, Akram NA (2013) Phytohormones and microRNAs as sensors and regulators of leaf senescence: assigning macro roles to small molecules. Biotechnol Adv. 31:1153-1171. 
Scarpella E (2017) The logic of plant vascular patterning. Polarity, continuity and plasticity in the formation of the veins and of their networks. Curr Opin Genet Dev. 45:3443.

Shwartz I, Matan L, Ori N, Bar M (2016) Hormones in tomato leaf development. Dev Biol. 419(1):132-142.

Tang D, Wang Y, Cai J, Zhao R (2009) Effects of exogenous application of plant growth regulators on the development of ovule and subsequent embryo rescue of stenospermic grape (Vitis vinifera L.). Sci Hortic-Amsterdam. 120(1):5157.

Toscano S, Trivellini A, Ferrante A, Romano D (2018) Physiological mechanisms for delaying the leaf yellowing of potted geranium plants. Sci Hortic-Amsterdam. 242:146-154.

Upadhyay A, Gaonkar T, Upadhyay AK, Jogaiah S, Shinde MP, Kadoo NY, Gupta VS (2018) Global transcriptome analysis of grapevine (Vitis vinifera L.) leaves under salt stress reveals differential response at early and late stages of stress in table grape cv. Thompson Seedless. Plant Physiol Bioch. 129:168-179.

Vidya Vardhini, B (2017) Modifications of morphological and anatomical characteristics of plants by application of brassinosteroids under various abiotic stress conditions - a review. Plant Gene. 11:70-89.

Vylíčilová H, Husicková A, Spíchal L, Srovnal J, Plíhal O, Plíhalová L (2016). C2-substituted aromatic cytokinin sugar conjugates delay the onset of senescence by maintaining the activity of the photosynthetic apparatus. Phytochemistry. 122:22-33.

Werner T, Schmülling T (2009) Cytokinin action in plant development. Curr Opin Plant Biol. 12:527-538.

Yang JC, Zhang JH, Wang ZQ, Zhu QS, Liu LJ (2003) Involvement of abscisic acid and cytokinins in the senescence and remobilization of carbon reserves in wheat subjected to water stress during grain filling. Plant Cell Environ. 26:1621-1631.

Yan J, Liao X, He R, Zhong M, Feng P, Li X, Tang D, Liu X, Zhao $X$ (2017) Ectopic expression of GA 2-oxidase 6 from rapeseed (Brassica napus L.) causes dwarfism, late flowering and enhanced chlorophyll accumulation in Arabidopsis thaliana. Plant Physiol Bioch. 111:10-19.

Yu YB, Yang SF (1979) Auxin-induced ethylene production and its inhibition by aminoethyoxyvinylglycine and cobalt ion. Plant Physiol. 64:1074-1077.

Zabadal TJ, Bukovac MJ (2006) Effect of CPPU on fruit development of selected seedless and seeded grape gultivars. HortScience 41:154-157.

Zhang Y, Wu X, Wang S, Niu H (2018) The simulation of the vine biomass at different planting ages in Ningxia vineyards using DNDC model. Acta Ecol Sin. 38(4): 281287.

Zoffoli JP, Latorre BA, Naranjo P (2009) Preharvest applications of growth regulators and their effect on postharvest quality of table grapes during cold storage. Postharvest Biol Tec. 51:183-192. 